\title{
A COMPARATIVE EVALUATION OF TWO TIVA TECHNIQUES FOR DAY CARE SURGICAL PROCEDURES- MIDAZOLAM AND KETAMINE VERSUS FENTANYL AND PROPOFOL
}

\author{
Veenita Sharma1, Vikrant Sharma², Bimlesh Kumar Mohindra ${ }^{3}$, Gurdeep Singh Sodhi ${ }^{4}$
}

${ }^{1}$ Associate Professor, Department of Anaesthesia and Critical Care, Mohri Shahabad, Haryana.

${ }^{2}$ Consultant, Department of Ophthalmology, Laser Eye Clinic, Chandigarh.

${ }^{3}$ Professor, Department of Anaesthesia and Critical Care, M. D. Oswal Cancer Treatment and Research Foundation, Ludhiana.

${ }^{4}$ Senior Consultant, Department of Anaesthesia and Critical Care, M. D. Oswal Cancer Treatment and Research Foundation, Ludhiana.

ABSTRACT
BACKGROUND
TIVA has gained popularity recently partly in order to reduce pollution by volatile agents. The present study was designed to
evaluate the comparison of Total intravenous anaesthesia (TIVA) techniques: Midazolam-Ketamine and Propofol-Fentanyl for their
cardiovascular effects, intraoperative and postoperative complications and recovery profile.

\section{MATERIALS AND METHODS}

The study was a non-randomised clinical trial. After approval of the hospital ethical committee, hundred patients from either sex ranging from 20-60 years of age, undergoing short surgical procedures less than an hour of ASA grade I and II were included in this study. The patients were randomly allocated into two Groups of 50 patients each. Group A received injection midazolam 0.05 $\mathrm{mg} / \mathrm{kg}$ IV and injection glycopyrrolate $0.2 \mathrm{mg}$ IV one minute before injection Ketamine $2 \mathrm{mg} / \mathrm{kg}$ IV given over 60 seconds. Thereafter ketamine infusion was started at $50 \mathrm{mcg} / \mathrm{kg} / \mathrm{min}$. Group B received injection fentanyl $2 \mathrm{mcg} / \mathrm{kg}$ IV. and injection glycopyrrolate $0.2 \mathrm{mg}$ IV one minute before the injection propofol $2.5 \mathrm{mg} / \mathrm{kg}$ IV given over 60 seconds. Thereafter, propofol infusion was started at $200 \mathrm{mcg} / \mathrm{kg} / \mathrm{min}$. The various parameters studied were induction time, pain on injection, heart rate, respiratory rate, $\mathrm{SpO}_{2}$, recovery time by using Modified Steward Coma Score.

\section{RESULTS}

In Group A, there was statistically significant rise in heart rate (HR) and mean arterial pressure (MAP) 15 minutes (T15) after induction whereas in Group B there was non-significant fall in HR 25 minutes after induction ( $\mathrm{T}_{25}$ ) but statistically significant fall in MAP at $\mathrm{T}_{5}$. Recovery profile was assessed by Modified Steward Coma Score. In Group A, maximum number of patients i.e. 25 patients have score of 6, 15 minutes after stopping ketamine infusion whereas in Group B 30 patients had score of 6, 5 minutes after stopping propofol infusion.

\section{CONCLUSION}

Out of two TIVA techniques, Group B is preferred as there was minimal changes in HR MAP and the near baseline values are restored earlier and patient had early recovery with less postoperative complication rate. On analyses based on discharge criterion, both the techniques are suitable for day care surgery.

\section{KEYWORDS}

TIVA, Day care surgery, Ketamine, Midazolam, Propofol, Fentanyl.

HOW TO CITE THIS ARTICLE: Sharma V, Sharma V, Mohindra BK, et al. A comparative evaluation of two TIVA techniques for day care surgical procedures- Midazolam and ketamine versus fentanyl and propofol. J. Evolution Med. Dent. Sci. 2017;6(87):60696076, DOI: $10.14260 /$ jemds/2017/1318

BACKGROUND
TIVA (Total intravenous Anaesthesia) technique became
practicable in early 1970s with the availability of rapid and
short-acting sedative-hypnotics and with the advent of non-
barbiturate induction agent propofol. This has refocused the
anaesthetist's attention on the complete provision, i.e.
induction as well as maintenance of anaesthesia by
intravenous route. TIVA has gained popularity recently partly
in order to reduce pollution by volatile agents.(1) TIVA
technique offers day-care anaesthesia and today many minor
Financial or Other Competing Interest': None.
Submission 09-10-2017, Peer Review 23-10-2017,
Acceptance 25-10-2017, Published 30-10-2017.
Corresponding Author:
Dr. Vikrant Sharma,
Laser Eye Clinic, SCO 833 834,
Sector 22 A, Chandigarh.
E-mail: dr_vikrant@yahoo.com
DOI: $10.14260 /$ jemds/2017/1318
@C) (1) @

procedures are performed on an outpatient basis. The goal for outpatient anaesthesia is to provide good perioperative anaesthesia with a minimum of postoperative side effects such as drowsiness, pain or nausea.(2) It also contributes to lower incidence of infection, respiratory complications and lower procedural cost. Ketamine, a phencyclidine is a dissociative intravenous anaesthetic agent that has many favourable characteristics, including amnesia, analgesia and bronchodilation.(3) However, the use of Ketamine as a sole anaesthetic agent is complicated by unpleasant emergence phenomena \& its sympathomimetic effect.(4) The sympathomimetic effect is thought to be due to centrally mediated release of catecholamines. Benzodiazepines have been reported to blunt the sympathomimetic effects and help to prevent emergence phenomena associated with Ketamine.(4) This is probably related to the central inhibitory and amnesic effects of benzodiazepines.(5) Midazolam is theoretically preferable to diazepam as its pharmacokinetic profile is similar to that of Ketamine.(6) Midazolam is a watersoluble benzodiazepine with a rapid onset and relatively 
short duration of action.(7) Ketamine has also been used as a continuous infusion for routine surgery ${ }^{(8)}$ and in combination with midazolam and vecuronium for military and civilian surgery.(9)

Although, there is still no gold standard for short outpatient anaesthesia, propofol has been claimed by many to be the best intravenous induction agent because of its good recovery profile.(2) Propofol has become the most widely used intravenous anaesthetic for TIVA due to its favourable pharmacokinetic and dynamic profile. It may be given as a single bolus or as a continuous infusion. It has no analgesic effect and is administered therefore in combination with potent analgesic.(1) When combined with an opioid like fentanyl, it can provide balanced anaesthesia.(10) There is no evidence of a pharmacokinetic interaction between propofol and fentanyl and their combination provides excellent clinical conditions.(11) Short-acting drugs allow better induction of anaesthesia and may therefore reduce the incidence of respiratory depression and permit rapid recovery which is especially desirable for day care surgery.(12)

There has been renewed interest in TIVA with the arrival of fentanyl and propofol on the Indian scene. Hence, this study was undertaken to evaluate and compare the two combinations i.e. midazolam - ketamine and fentanylpropofol for TIVA technique in day care surgical procedures. These combinations were compared for their cardiovascular effects, intraoperative and postoperative complications and recovery profile.

\section{MATERIALS AND METHODS}

The study was conducted in Department of Anaesthesiology and Critical Care, Mohan Dai Oswal Cancer Treatment and Research Foundation, Ludhiana. It was a non-randomised clinical trial. Since it was a pilot trial, we took the sample size of 50 patients in each group for convenience. After approval of the Hospital Ethical Committee, hundred patients from either sex ranging from 20-60 years of age, undergoing short surgical procedures less than one hour of ASA grade I \& II were included in this study. Patients excluded were those with history of allergy to any particular drug or egg allergy or previous adverse response to General Anaesthesia, patients with history of any psychiatric illness, pregnant females, patients on MAO inhibitors, history of jaundice, addiction to any drug particularly narcotics, patients having severe anaemia, hypertension, morbidly obese patients. The patients who met the inclusion criteria were alternately allocated to one of the two groups. All patients were examined in preanaesthetic clinic the day prior to surgery. A written informed consent from the patient was taken in the presence of his/her relatives. All patients were given Tab. Diazepam 10 mg orally a night before surgery. All patients were kept fasting for six hours prior to surgery.

\section{Anaesthesia Technique}

After shifting the patient on operation table, intravenous line was established. Basal recordings of systolic, diastolic and mean blood pressures (SBP, DBP, and MAP), heart rate (HR), and arterial saturation of oxygen $\left(\mathrm{SpO}_{2}\right)$ on air were noted. These observations were made before induction, one minute after induction, and every 5 minutes till the end of procedure. Patients were kept on spontaneous ventilation, i.e. on room air. During the procedure, $\mathrm{SpO}_{2}$ was monitored and $100 \% \mathrm{O}_{2}$ was given by face mask if $\mathrm{SpO}_{2}$ fell below $90 \%$. Hundred patients were randomly allocated into two groups of fifty patients.

\section{Group A}

Received injection midazolam $0.05 \mathrm{mg} / \mathrm{kg}$ IV and injection glycopyrrolate $0.2 \mathrm{mg}$ IV one minute before injection ketamine $2 \mathrm{mg} / \mathrm{kg}$ IV given over 60 seconds. Thereafter, ketamine infusion was started at $50 \mathrm{mcg} / \mathrm{kg} /$ minute.

\section{Group B}

Received injection fentanyl $2 \mathrm{mcg} / \mathrm{kg}$ IV and injection glycopyrrolate $0.2 \mathrm{mg}$ IV one minute before injection propofol $2.5 \mathrm{mg} / \mathrm{kg}$ IV given over 60 seconds. Thereafter, propofol infusion was started at $200 \mathrm{mcg} / \mathrm{kg} / \mathrm{minute}$. For both groups $20 \mathrm{ml}$ syringe was used for infusion, with Ketamine and Propofol as $1 \%$ solution. Syringe pump by Tzamal care SEP-10S was used for infusion.

The following observations were recorded - induction time, pain on injection and recovery time. Induction time was assessed by central fixation of eyeballs in case of ketamine anaesthesia and loss of eyelash reflex in case of propofol anaesthesia. Recovery from anaesthesia was assessed by Modified Steward Coma Score.(13)

\begin{tabular}{|c|c|}
\hline Consciousness & Points \\
\hline Fully awake, eyes open, conversing & 4 \\
\hline Light asleep, eyes open intermittently & 3 \\
\hline Eyes open on command or in response to name & 2 \\
\hline Responding to ear pinching & 1 \\
\hline Not responding & 0 \\
\hline Airway & 3 \\
\hline $\begin{array}{c}\text { Opening mouth } \pm \text { coughing on command } \\
\text { No voluntary cough but airway clear without } \\
\text { support }\end{array}$ & 2 \\
\hline $\begin{array}{c}\text { Airway obstruction on neck flexion but clear } \\
\text { without Support on extension }\end{array}$ & 1 \\
\hline Airway obstruction without support & 0 \\
\hline Activity & 2 \\
\hline Raising one arm on command & 1 \\
\hline Non-purposeful movement & 0 \\
\hline Not moving 1. Modified Steward Coma Score \\
\hline \multicolumn{2}{|c|}{} \\
\hline
\end{tabular}

The score was calculated at 1, 3, 5, 10 \& 15 minutes from the end of procedure and at discharge from the recovery room. In the post-op period, following vitals (BP, HR, RR and $\mathrm{SpO}_{2}$ ) were recorded and any complications/side effects like nausea, vomiting, respiratory depression, emergence reaction were recorded.

\section{Statistical Analysis}

\section{The Results were Analysed by using the following Statistical Tests}

In order to compare different parameters at different points of time, both intra as well as intergroup, student's t-test was applied. The mean values of different parameters in two groups were also compared by applying the same test. Z-test was applied to compare two proportions of subjects. Chisquare $\left(\mathrm{X}^{2}\right)$ test was applied to see the association of groups with sex. 


\section{RESULTS}

A total of 100 patients of either gender scheduled for short day care procedures were prospectively evaluated. The demographic parameters of sex, weight and age in both the groups were comparable. [Table 2].

\begin{tabular}{|c|c|c|}
\hline $\begin{array}{c}\text { Demographic } \\
\text { Parameter }\end{array}$ & Group A & Group B \\
\hline Age (in years) & $45.28 \pm 11.44$ & $41.12 \pm 11.86$ \\
\hline Sex (Male/Female) & $22 / 28$ & $17 / 33$ \\
\hline Weight (Kg) & $57.34 \pm 6.14$ & $55.14 \pm 5.67$ \\
\hline $\begin{array}{c}\text { Duration of surgery } \\
\text { (min.) }\end{array}$ & $17.00 \pm 6.06$ & $18.20 \pm 7.41$ \\
\hline \multicolumn{3}{|c}{ Table 2 } \\
\hline
\end{tabular}

\begin{tabular}{|c|c|c|}
\hline $\begin{array}{c}\text { Duration of } \\
\text { surgery } \\
\text { (in minutes) }\end{array}$ & Group A & Group B \\
\hline 10 & $14(28)$ & $14(28)$ \\
\hline 15 & $13(26)$ & $13(26)$ \\
\hline 20 & $16(32)$ & $8(16)$ \\
\hline 25 & $4(8)$ & $2(4)$ \\
\hline 30 & $2(4)$ & $10(20)$ \\
\hline 35 & $1(2)$ & $3(6)$ \\
\hline Mean \pm SD & $17.00 \pm 6.06$ & $18.20 \pm 7.41$ \\
\hline \multicolumn{2}{|c|}{ Table 3. Distribution of Duration of Surgery } \\
\hline
\end{tabular}

Figures in parenthesis indicate percentage $\mathrm{t}$ - value $=0.89$ $\mathrm{p}$-value $>0.05$ (non-significant)

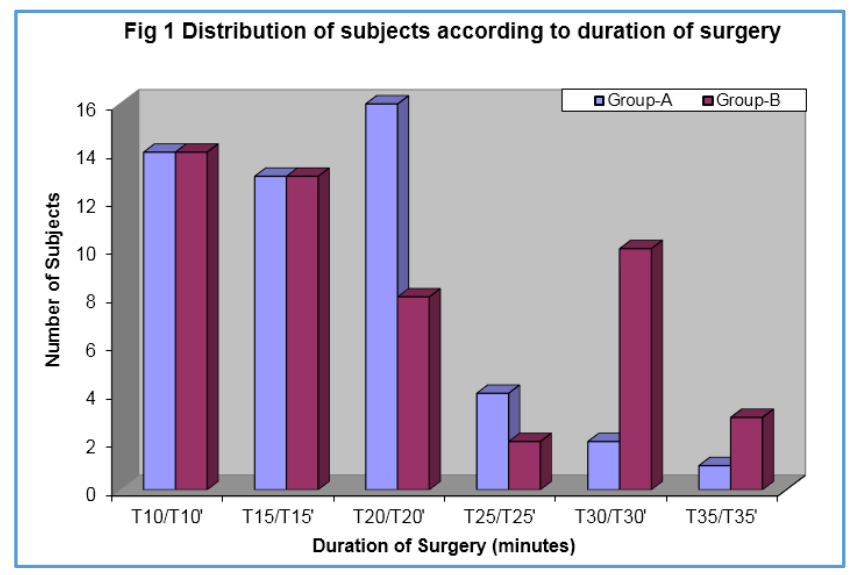

\section{Pain on Injection}

In Group A, no patient had pain on injection as compared to Group B, in which 15 patients had pain on injection with statistically significant difference between the two groups. (p-value < 0.01). (Table 4) (Fig. 2).

\begin{tabular}{|c|c|c|}
\hline Pain on Injection & Group A & Group B \\
\hline Yes & $0(0)$ & $15(30)$ \\
\hline No & $50(100)$ & $35(70)$ \\
\hline Table 4. Distribution of Patients having Pain on Injection \\
\hline
\end{tabular}

Figures in parenthesis indicate percentage; $\mathrm{z}$ - value $=$ 3.33, p- value $<0.01$ (significant).

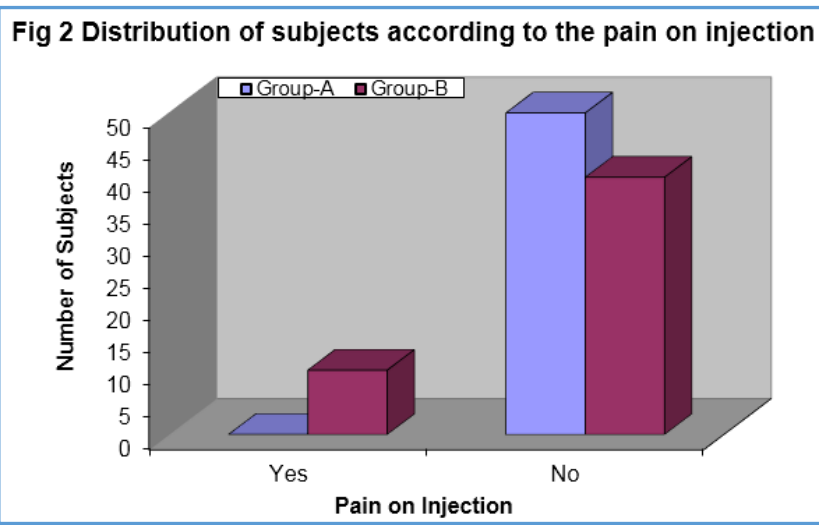

The range of induction time in Group A was 18-24 seconds and in Group B, it was 36-42 seconds. The mean induction time in Group A was $21.30 \pm 1.62$ and in Group B was $38.52 \pm 2.01$ with significant statistical difference between the two groups $(\mathrm{p}<0.01)$. (Table 5$)$.

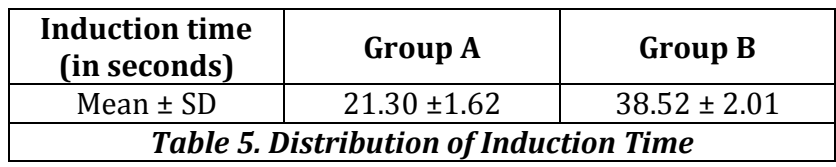

$\mathrm{t}$ - value $=47.17, \mathrm{p}$ - value $<0.01$ (significant) .

The observations of heart rate (HR), mean arterial blood pressure (MAP), arterial oxygen saturation $\left(\mathrm{SpO}_{2}\right)$ and respiratory rate (RR) were recorded at various points of time. In Group $\mathrm{A}$, basal readings $\left(\mathrm{T}_{\mathrm{o}}\right)$ were recorded prior to induction of anaesthesia, $\left(\mathrm{T}_{1}\right)$ one minute after induction of anaesthesia and then five minutes after induction of anaesthesia till the completion of procedure i.e. $\left(T_{5}, T_{10}\right.$, $\left.\mathrm{T}_{15}, \ldots \ldots \ldots . . . ..\right)$. Similarly in Group $\mathrm{B}$, readings were recorded at $\mathrm{T}_{\mathrm{o}}{ }^{\prime}, \mathrm{T}_{1}{ }^{\prime}, \mathrm{T}_{5}{ }^{\prime}, \mathrm{T}_{10}{ }^{\prime}, \mathrm{T}_{15}{ }^{\prime}, \ldots \ldots \ldots$.... till the end of surgery.

The mean of basal value of heart rate $\left(\mathrm{T}_{\mathrm{o}}\right)$ was $85.16 \pm$ 8.23 beats per minute in Group $\mathrm{A}$ and $\mathrm{T}_{\mathrm{o}}{ }^{\prime}$ was $85.32 \pm 8.29$ beats per minute in Group B with no statistically significant difference between them ( $p$-value $>0.05$ ). In group $A$, the maximum increase $(35.5 \%)$ in heart rate was at $T_{15}$ from the basal heart rate at $\mathrm{T}_{\mathrm{o}}$ with statistically significant difference between them $\left(\mathrm{T}_{0}\right.$ and $\left.\mathrm{T}_{15}\right)$ ( $\mathrm{p}$-value $\left.<0.01\right)$. In Group $\mathrm{B}$, the maximum fall of $(-2.91 \%)$ was at $\mathrm{T}_{25}$, from the basal heart rate at $\mathrm{T}_{\mathrm{o}}{ }^{\prime}$ with statistically non-significant difference between them ( $\mathrm{T}_{\mathrm{o}}{ }^{\prime}$ and $\mathrm{T}_{25}{ }^{\prime}$ ) (p-value 0.05). (Table 6, Fig. 3).

\begin{tabular}{|c|c|c|}
\hline $\begin{array}{c}\text { Time Intervals } \\
\text { (in minutes) }\end{array}$ & Group A & Group B \\
\hline $\mathrm{T}_{\mathrm{o}} / \mathrm{T}_{\mathrm{o}}{ }^{\prime}$ & $85.16 \pm 8.23(50)$ & $85.32 \pm 8.29(50)$ \\
\hline $\mathrm{T}_{1} / \mathrm{T}_{1}{ }^{\prime}$ & $95.84 \pm 9.29(50)$ & $87.52 \pm 9.09(50)$ \\
\hline $\mathrm{T}_{5} / \mathrm{T}_{5}{ }^{\prime}$ & $106.54 \pm 8.48(50)$ & $86.88 \pm 7.75(50)$ \\
\hline $\mathrm{T}_{10} / \mathrm{T}_{10}{ }^{\prime}$ & $112.28 \pm 7.47(50)$ & $85.68 \pm 7.72(50)$ \\
\hline $\mathrm{T}_{15} / \mathrm{T}_{15}{ }^{\prime}$ & $115.39 \pm 7.63(36)$ & $86.22 \pm 8.46(36)$ \\
\hline $\mathrm{T}_{20} / \mathrm{T}_{20}{ }^{\prime}$ & $113.55 \pm 8.13(22)$ & $86.24 \pm 8.05(25)$ \\
\hline $\mathrm{T}_{25} / \mathrm{T}_{25}{ }^{\prime}$ & $109.71 \pm 11.14(7)$ & $82.83 \pm 6.87(12)$ \\
\hline $\mathrm{T}_{30} / \mathrm{T}_{30}{ }^{\prime}$ & $100.00 \pm 11.55(3)$ & $85.60 \pm 5.77(5)$ \\
\hline $\mathrm{T}_{35} / \mathrm{T}_{35}{ }^{\prime}$ & $114.00 \pm(1)$ & $80.00 \pm 6.00(2)$ \\
\hline \multicolumn{3}{|c|}{ Table 6. Trends in Heart Rate } \\
\hline \multicolumn{3}{|c}{}
\end{tabular}

Figures in parenthesis indicate number of patients in the group. 


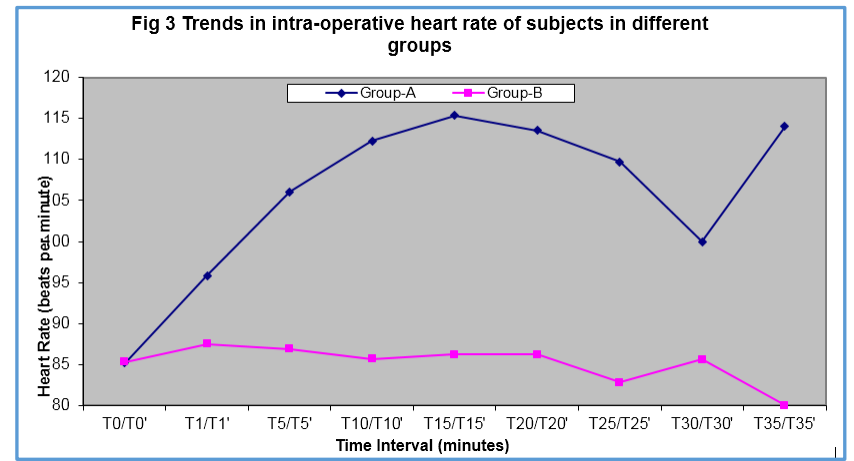

The mean of basal value of Mean Arterial Pressure at $\mathrm{T}_{\mathrm{o}}$ in Group A was $95.59 \pm 8.21 \mathrm{mmHg}$ and in Group B at $\mathrm{T}_{\mathrm{o}}{ }^{\prime}$ was $98.03 \pm 8.56 \mathrm{mmHg}$ with statistically non-significant difference between them ( $p$-value $>0.05$ ).

In Group A, there was a rise in MAP $(24.9 \%)$ at $\mathrm{T}_{15}$ with mean value of $119.38 \pm 7.24 \mathrm{mmHg}$ from the basal value of $95.59 \pm 8.21 \mathrm{mmHg}$ at $\mathrm{T}_{\mathrm{o}}$ with statistically significant difference between the two values. $\left(\mathrm{T}_{\mathrm{o}}\right.$ and $\left.\mathrm{T}_{15}\right)$ ( $\mathrm{p}$-value $<$ 0.01).

In Group B, there was a fall in MAP $(-12.03 \%)$ at $\mathrm{T}_{5}{ }^{\prime}$ with mean value of $86.24 \pm 7.38 \mathrm{mmHg}$ from the basal value of $98.03 \pm 8.56 \mathrm{mmHg}$ at $\mathrm{T}_{\mathrm{o}}{ }^{\prime}$ with statistically significant difference between the two values. $\left(\mathrm{T}_{\mathrm{o}}{ }^{\prime}\right.$ and $\left.\mathrm{T}_{5}{ }^{\prime}\right)$ ( $\mathrm{p}$-value < 0.01). (Table 7, Fig. 4)

\begin{tabular}{|c|c|c|}
\hline $\begin{array}{c}\text { Time Intervals } \\
\text { (in minutes) }\end{array}$ & Group A & Group B \\
\hline $\mathrm{T}_{\mathrm{o}} / \mathrm{T}_{\mathrm{o}}{ }^{\prime}$ & $95.59 \pm 8.21(50)$ & $98.03 \pm 8.56(50)$ \\
\hline $\mathrm{T}_{1} / \mathrm{T}_{1}{ }^{\prime}$ & $103.27 \pm 8.45(50)$ & $96.43 \pm 8.06(50)$ \\
\hline $\mathrm{T}_{5} / \mathrm{T}_{5}{ }^{\prime}$ & $111.20 \pm 7.57(50)$ & $86.24 \pm 7.38(50)$ \\
\hline $\mathrm{T}_{1 \mathrm{o}} / \mathrm{T}_{1 \mathrm{o}}{ }^{\prime}$ & $116.03 \pm 6.57(50)$ & $91.90 \pm 6.88(50)$ \\
\hline $\mathrm{T}_{15} / \mathrm{T}_{15}{ }^{\prime}$ & $119.38 \pm 7.24(36)$ & $92.97 \pm 6.84(36)$ \\
\hline $\mathrm{T}_{2 \mathrm{o}} / \mathrm{T}_{2 \mathrm{o}}{ }^{\prime}$ & $119.39 \pm 6.41(22)$ & $94.50 \pm 6.61(25)$ \\
\hline $\mathrm{T}_{25} / \mathrm{T}_{25}{ }^{\prime}$ & $112.00 \pm 6.71(7)$ & $94.37 \pm 6.67(12)$ \\
\hline $\mathrm{T}_{3 \mathrm{o}} / \mathrm{T}_{3 \mathrm{o}}{ }^{\prime}$ & $105.78 \pm 7.17(3)$ & $97.17 \pm 7.59(5)$ \\
\hline $\mathrm{T}_{35} / \mathrm{T}_{35}{ }^{\prime}$ & $97.34 \pm(1)$ & $96.23 \pm 8.51(2)$ \\
\hline
\end{tabular}
group.

Figures in parenthesis indicate number of patients in the

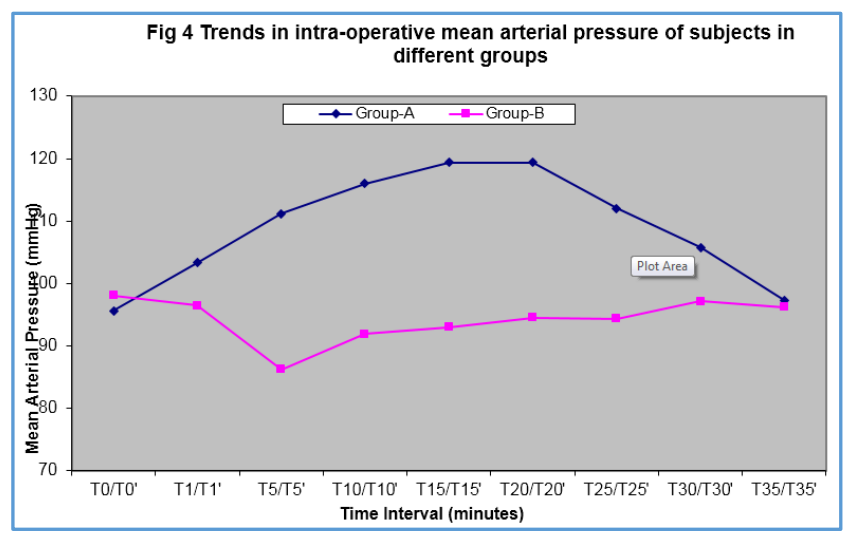

The mean of basal value of Respiratory Rate at $\mathrm{T}_{0}$ in Group A was $15.00 \pm 2.03$ breaths per minute and in Group B at $\mathrm{T}_{\mathrm{o}}{ }^{\prime}$ was $16.02 \pm 3.44$ breaths per minutes with statistically non-significant difference between them ( $p$-value $>0.05$ ) In Group A, there was a rise in $\mathrm{RR}(11.47 \%)$ at $\mathrm{T}_{1 \mathrm{o}}$ with the mean value of $16.72 \pm 2.05$ breaths per minute from the basal value of $15.00 \pm 2.03$ breaths per minute at $\mathrm{T}_{0}$ with statistically significant difference between the two values $\left(\mathrm{T}_{\mathrm{o}}\right.$ and $\mathrm{T}_{10}$ ) (p-value $<0.01$ ) In Group B, there was a fall in RR ($30.83 \%$ ) at $\mathrm{T}_{5}$ ' with the mean value of $11.08 \pm 2.16$ breaths per minute from the basal value of $16.02 \pm 3.44$ breaths per minute at $\mathrm{T}_{\mathrm{o}}$ ' with statistically significant difference between the two values $\left(\mathrm{T}_{\mathrm{o}}{ }^{\prime}\right.$ and $\left.\mathrm{T}_{5}{ }^{\prime}\right)$ ( $\mathrm{p}$-value $<0.01$ ) (Table 8 Fig. 5).

\begin{tabular}{|c|c|c|}
\hline $\begin{array}{c}\text { Time Intervals } \\
\text { (in minutes) }\end{array}$ & Group A & Group B \\
\hline $\mathrm{T}_{\mathrm{o}} / \mathrm{T}_{\mathrm{o}}{ }^{\prime}$ & $15.00 \pm 2.03(50)$ & $16.02 \pm 3.44(50)$ \\
\hline $\mathrm{T}_{1} / \mathrm{T}_{1}{ }^{\prime}$ & $15.60 \pm 2.06(50)$ & $15.08 \pm 2.07(50)$ \\
\hline $\mathrm{T}_{5} / \mathrm{T}_{5}{ }^{\prime}$ & $15.88 \pm 2.37(50)$ & $11.08 \pm 2.16(50)$ \\
\hline $\mathrm{T}_{10} / \mathrm{T}_{10}{ }^{\prime}$ & $16.72 \pm 2.05(50)$ & $13.36 \pm 2.23(50)$ \\
\hline $\mathrm{T}_{15} / \mathrm{T}_{15}{ }^{\prime}$ & $16.33 \pm 1.87(36)$ & $14.33 \pm 2.26(36)$ \\
\hline $\mathrm{T}_{2 \mathrm{o}} / \mathrm{T}_{2 \mathrm{o}}{ }^{\prime}$ & $15.57 \pm 1.78(22)$ & $14.52 \pm 2.32(25)$ \\
\hline $\mathrm{T}_{25} / \mathrm{T}_{25}{ }^{\prime}$ & $15.50 \pm 1.34(7)$ & $14.50 \pm 2.35(12)$ \\
\hline $\mathrm{T}_{30} / \mathrm{T}_{3 \mathrm{o}}{ }^{\prime}$ & $16.67 \pm 2.52(3)$ & $14.67 \pm 2.52(5)$ \\
\hline $\mathrm{T}_{35} / \mathrm{T}_{35}{ }^{\prime}$ & $18.00 \pm(1)$ & $16.67 \pm 2.52(2)$ \\
\hline \multicolumn{3}{|c|}{ Table 8. Trends in Respiratory Rate } \\
\hline \multicolumn{2}{|c|}{}
\end{tabular}

Figures in parenthesis indicate number of patients in the Group.

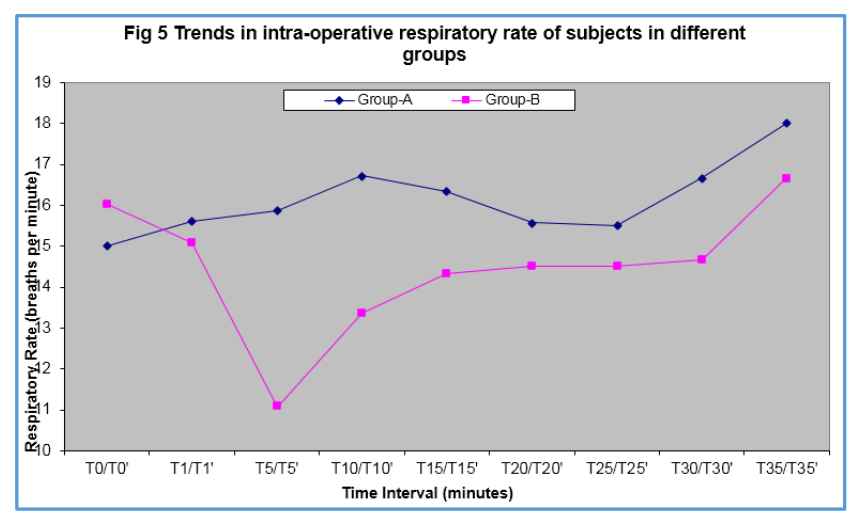

The mean of basal value of $\mathrm{SpO}_{2}$ at $\mathrm{T}_{\mathrm{o}}$ in Group A was $97.52 \pm 1.79 \%$ and in Group B, was $97.16 \pm 1.90 \%$ at $\mathrm{T}_{\mathrm{o}}{ }^{\prime}$ with statistically non-significant difference between them $\left(\mathrm{T}_{\mathrm{o}}\right.$ and $\mathrm{T}_{\mathrm{o}}{ }^{\prime}$ ) (p-value>0.05). In Group $\mathrm{A}$, there was fall in $\mathrm{SpO}_{2}$ $(-2.67 \%)$ at $\mathrm{T}_{1 \mathrm{o}}$ and in Group $\mathrm{B}$, there was fall in $\mathrm{SpO}_{2}$ at $\mathrm{T}_{5}{ }^{\prime}$ $(-6.83 \%)$ with statistically significant difference (p-value $<0.01$ ) from the basal $\mathrm{SpO}_{2}$ within both the groups i.e. between $\mathrm{T}_{\mathrm{o}}$ and $\mathrm{T}_{1 \mathrm{o}}$ and $\mathrm{T}_{1 \mathrm{o}}$ in Group $\mathrm{A}$ and $\mathrm{T}_{\mathrm{o}}$ ' and $\mathrm{T}_{5}$ ' in Group B. (Table 9).

\begin{tabular}{|c|c|c|}
\hline $\begin{array}{c}\text { Time Intervals } \\
\text { (in minutes) }\end{array}$ & Group A & Group B \\
\hline $\mathrm{T}_{\mathrm{o}} / \mathrm{T}_{\mathrm{o}}{ }^{\prime}$ & $97.52 \pm 1.79(50)$ & $97.16 \pm 1.90(50)$ \\
\hline $\mathrm{T}_{1} / \mathrm{T}_{1}{ }^{\prime}$ & $96.24 \pm 1.44(50)$ & $95.88 \pm 1.87(50)$ \\
\hline $\mathrm{T}_{5} / \mathrm{T}_{5}{ }^{\prime}$ & $95.00 \pm 2.56(50)$ & $90.52 \pm 3.35(50)$ \\
\hline $\mathrm{T}_{10} / \mathrm{T}_{10}{ }^{\prime}$ & $94.92 \pm 2.36(50)$ & $92.68 \pm 1.65(50)$ \\
\hline $\mathrm{T}_{15} / \mathrm{T}_{15}{ }^{\prime}$ & $95.47 \pm 1.95(36)$ & $94.11 \pm 2.13(36)$ \\
\hline $\mathrm{T}_{20} / \mathrm{T}_{20}{ }^{\prime}$ & $95.65 \pm 1.54(22)$ & $94.22 \pm 2.01(25)$ \\
\hline $\mathrm{T}_{25} / \mathrm{T}_{25}{ }^{\prime}$ & $95.25 \pm 1.41(7)$ & $94.60 \pm 2.56(12)$ \\
\hline $\mathrm{T}_{30} / \mathrm{T}_{30}{ }^{\prime}$ & $94.00 \pm 1.65(3)$ & $96.00 \pm 2.86(5)$ \\
\hline $\mathrm{T}_{35} / \mathrm{T}_{35}{ }^{\prime}$ & $94.00 \pm(1)$ & $94.00 \pm 0.00(2)$ \\
\hline \multicolumn{3}{|c|}{ Table 9. Trends in SpO2 } \\
\hline
\end{tabular}

Figures in parenthesis indicate number of patients in the group. 
In Intraoperative period, the incidence of respiratory depression in both the groups were studied. In Group A, 5 patients had respiratory depression and in Group B, 16 patients had respiratory depression with a statistical significant difference between the two groups. (p-value < 0.01) (Table 10, Fig. 6).

\begin{tabular}{|c|c|c|}
\hline $\begin{array}{c}\text { Incidence of Respiratory } \\
\text { Depression }\end{array}$ & Group A & Group B \\
\hline Yes & $5(10)$ & $16(32)$ \\
\hline No & $45(90)$ & $34(68)$ \\
\hline \multicolumn{2}{|c|}{ Table 10. Incidence of Intraoperative Complications } \\
\hline
\end{tabular}

Figures in parenthesis indicate percentage, $z$-value $=2.70, p$ value $<0.01$ (significant).

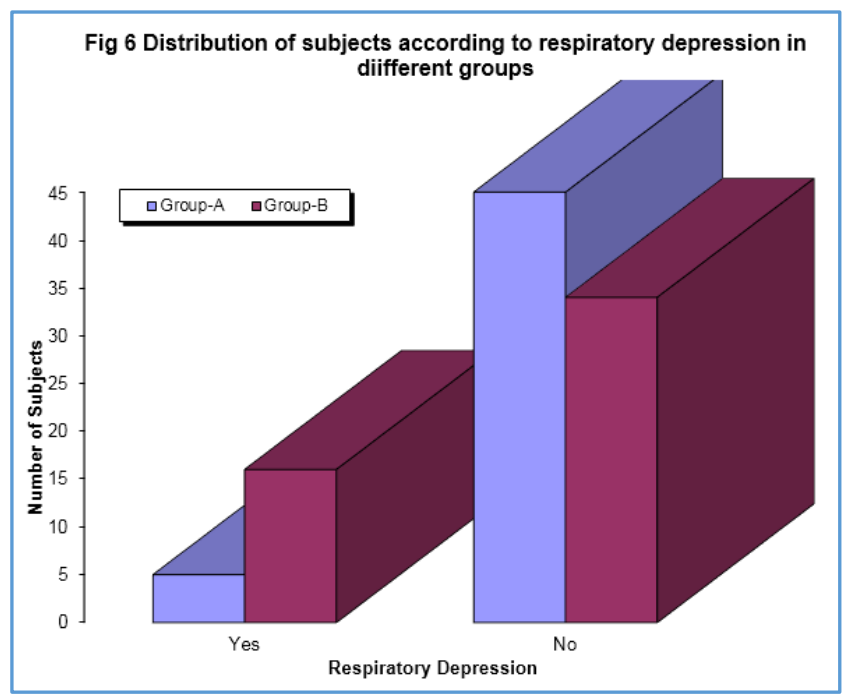

In postoperative period, the incidence of emergence delirium, nausea and vomiting in both the groups were studied. In Group A, 8 patients had emergence delirium and 16 patients had nausea and vomiting. In Group B, no patient had emergence delirium and 5 patients had nausea and vomiting with a statistical significant difference between the two groups ( $\mathrm{p}$-value< 0.01) (Table 11).

\begin{tabular}{|c|c|c|}
\hline Group & $\begin{array}{c}\text { Emergence Delirium } \\
\text { (Number of Patients) }\end{array}$ & $\begin{array}{c}\text { Nausea and Vomiting } \\
\text { (Number of Patients) }\end{array}$ \\
\hline A & $8(16)$ & $16(32)$ \\
\hline B & $0(-)$ & $5(10)$ \\
\hline Z-value & 2.95 & 2.70 \\
\hline p-value & $<0.01$ (significant) & $<0.01$ (significant) \\
\hline \multicolumn{2}{|c|}{ Table 11. Incidence of Postoperative Complications } \\
\hline
\end{tabular}

Figures in parenthesis indicate percentage.

\section{Variations in Recovery Profile of Patients Acquiring Modified Steward Coma Score of Six}

In Group A and Group B, recovery of patients was assessed at $\left(\mathrm{ST}_{1} / \mathrm{ST}_{1}{ }^{\prime}\right),\left(\mathrm{ST}_{3} / \mathrm{ST}_{3}{ }^{\prime}\right),\left(\mathrm{ST}_{5} / \mathrm{ST}_{5}{ }^{\prime}\right),\left(\mathrm{ST}_{1 \mathrm{o}} / \mathrm{ST}_{10}{ }^{\prime}\right),\left(\mathrm{ST}_{15} / \mathrm{ST}_{15}{ }^{\prime}\right)$ i.e. at $1,3,5,10,15$ minutes after stoppage of infusion of both the respective drugs. The numbers of patients having score of six at a particular time were studied. In Group A, the mean of patients having score of six was $11.42 \pm 4.10$ minutes and in Group B, it was $5.50 \pm 3.14$ with statistically significant difference between the two groups. (p-value <0.01) (Table 12, Fig. 7).

\begin{tabular}{|c|c|c|}
\hline Time Interval (in minutes) & Group A & Group B \\
\hline $\mathrm{ST}_{1} / \mathrm{ST}_{1}^{\prime}$ & $0(-)$ & $5(10)$ \\
\hline $\mathrm{ST}_{3} / \mathrm{ST}_{3}^{\prime}$ & $2(4)$ & $5(10)$ \\
\hline $\mathrm{ST}_{5} / \mathrm{ST}_{5}{ }^{\prime}$ & $8(16)$ & $30(60)$ \\
\hline $\mathrm{ST}_{10} / \mathrm{ST}_{10}{ }^{\prime}$ & $15(30)$ & $8(16)$ \\
\hline $\mathrm{ST}_{15} / \mathrm{ST}_{15}{ }^{\prime}$ & $25(50)$ & $2(4)$ \\
\hline Mean \pm SD & $11.42 \pm 4.10$ & $5.50 \pm 3.14$ \\
\hline
\end{tabular}

Figures in parenthesis indicate percentage, $t$-value $=8.11$, p-value $<0.01$ (significant).

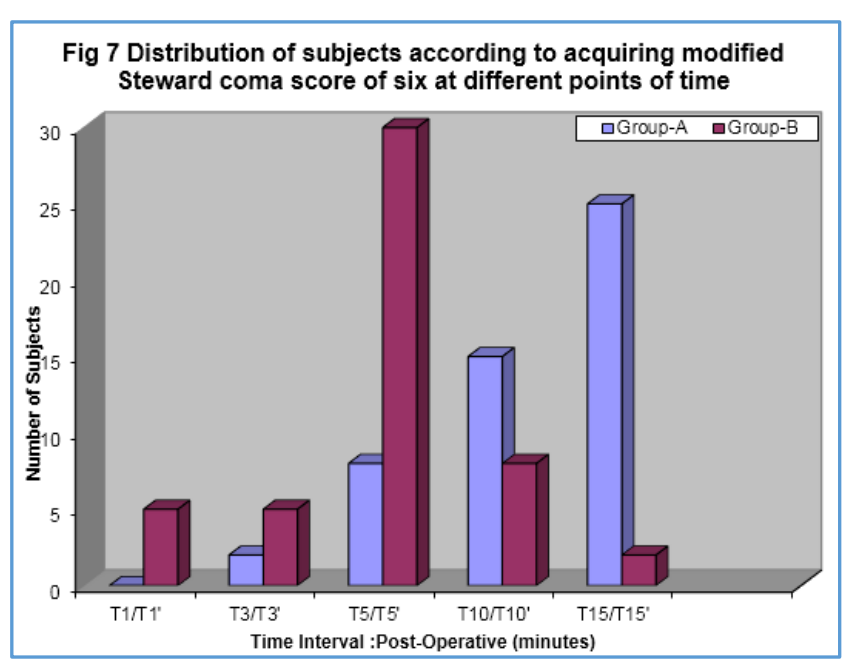

\section{DISCUSSION}

Total intravenous anaesthesia offers day-care anaesthesia and the availability of rapid, shorter acting anaesthetic, analgesic drugs have facilitated the recovery process, allowing more extensive procedures to be performed on a wide variety of outpatients.(14) The drugs used in the present study i.e. midazolam, fentanyl, ketamine, propofol also fulfil the conditions applicable to be used for day care surgery, hence providing greater flexibility in scheduling operation, low morbidity and mortality, lower incidence of infection and respiratory complications, shorter surgical lists, lower overall procedural costs, less preoperative testing and postoperative medication.

The combination of ketamine with shorter acting, water soluble, less irritant benzodiazepine-midazolam was evaluated in our study as it eliminates emergence delirium which was demonstrated by Cartwright and Pingle.(5) Similarly, Langrehr D et al and White PF found that benzodiazepines also cause muscle relaxation, anxiolysis, central sedation and attenuates cardiostimulatory response of ketamine.(15),(16) In the other combination, short opioid fentanyl was combined to provide analgesia since propofol lacks analgesic effect.

In our study, in Group A no patient had pain on injection because of non-irritant effect of midazolam and ketamine. In Group B, 15 (30\%) patients had pain on injection propofol which was comparable to study by Klement W., Arndt J.O. which showed $30 \%$ to $90 \%$ incidence of pain on injection of propofol.(17) The incidence of pain on injection can be decreased by injection into large veins as was demonstrated by lrwin MG et al.(13)

In Group A, the induction time was 18-24 seconds \{ketamine has onset of action within 30 seconds and peak effect in 1 minute (Ronald D Miller)\}. The induction time was 
assessed by central fixation of eyeballs after injection ketamine. In Group B, the induction time was 36-42 seconds (The peak effect of propofol is attained at 90-100 seconds as demonstrated by Rolly G, Verseichellen L et al ${ }^{(18)}$ ).

In our study, the maximum increase in heart rate in Group A was $35.5 \%$ after 15 minutes from the baseline value. A similar study by Chudnofsky et al showed the increase in heart rate by $25 \%$. The higher heart rate in our group is probably due to the additive effect of glycopyrrolate as in their group premedication with glycopyrrolate was not used. In our study in Group A, the maximum rise in MAP (24.9\%) from the baseline value was after 15 minutes which was comparable to MAP changes shown by Chudnofsky CR et al.(19)

In the present study, ketamine did result in a transient increase in MAP and heart rate. However, this was well tolerated as no patient required treatment for hypertension or experienced any cardiovascular or central nervous system sequelae. Ketamine inhibits the reuptake of catecholamines, resulting in mild-to-moderate increases in blood pressure, heart rate and cardiac output which were shown by Reich DL et al and white PF et al.(3) (20) Hernandez et al compared three TIVA techniques and found significant higher number of hypertensive peaks in midazolam-ketamine group.(21) Similar results have been shown by Krithika et al.(22) Fortunately, stimulation of the cardiovascular system may by blunted with concurrent administration of a benzodiazepine was also shown by Reich DL et al in 1989.(3)

In our study, in Group B, there was statistically nonsignificant fall in heart rate $(-2.91 \%)$ from the baseline value which is comparable to study done by Jenstrup $M$ et al(1) which also showed only slight change in heart rate in fentanyl-propofol anaesthesia. In Group B, there was significant reduction in mean arterial pressure $(-12.03 \%)$ from the baseline value, 5 minutes after induction of anaesthesia which is comparable to the fall in mean arterial pressure as demonstrated by Jenstrup $M$ et al and by Vermeyen MM et al.(1),(23) This fall in mean arterial pressure is due to the combined hypotensive effect of both mean blood propofol concentration being at or slightly above the target value within 5 minutes of commencing the infusion. Similarly, in our study, the maximum hypotensive effect was produced after 5 minutes.

In our study, the maximum increase in respiratory rate $(11.47 \%)$ in Group A, from baseline value was after 10 minutes of induction of anaesthesia. There was fall in $\mathrm{SpO}_{2}$ ($2.67 \%$ ) from baseline value, 10 minutes after induction of anaesthesia.

In Group B, there was maximum decrease in respiratory rate $(-30.83 \%)$ from the baseline value, 5 minutes after the induction. The minimum breaths per minute which the patients had were 9 and the respiratory rate did not recover to baseline, even after 25 minutes. This fall in respiratory rate is due to the combined apnoeic effect of fentanyl and propofol as shown by Gill SS et al.(24) There was accompanied fall in $\mathrm{SpO}_{2}(-6.83 \%)$ to lowest value of $84 \%$.

The postoperative recordings of haemodynamic and respiratory variables were not comparable because of variable duration of procedures, so they were not considered in the study.

In both the groups, the incidence of respiratory depression was studied as the major intraoperative complication. Respiratory depression was considered if there was fall in $\mathrm{SpO}_{2}$ below $90 \%$ and patient required oxygen supplementation.

In Group A, 5 (10\%) patients had respiratory depression with a maximum fall in $\mathrm{SpO}_{2}$ of $88 \%$ which recovered soon after oxygenating the patients with $100 \%$ oxygen. Out of these, 2 patients had history of chronic bronchitis. The rest 3 patients were obese. The study by Chudnofsky et al showed respiratory depression incidence of $4 \% .{ }^{(19)}$

In Group B, 16 (32\%) patients had respiratory depression with fall of $\mathrm{SpO}_{2}$ below $90 \%$, who were supplemented with $100 \%$ oxygen. In these patients, oxygen supplementation was continued till the end of procedure. The Maximum fall in $\mathrm{SpO}_{2}$ was up to $84 \%$ which improved, but did not recover to baseline value till the end of procedure. The high incidence in respiratory depression with fentanyl \& propofol group was due to combined apnoeic effect of both, as commented by Sanderson JH and Taylor MB in their study.(25),(26)

In both the groups, the incidence of emergence delirium and nausea and vomiting was noted in postoperative period. In Group A, 8 (16\%) patients had emergence delirium in postoperative period as compared to Group B in which no patient had emergence delirium. In Chudnofsky et al study, $7 \%$ of patients had emergence delirium.(19) The variation in incidence could be explained, as the dose of midazolam we have used $(0.05 \mathrm{mg} / \mathrm{kg})$ is less than the dose of midazolam $(0.07 \mathrm{mg} / \mathrm{kg})$ they have used.

The incidence of vomiting in Group A was $32 \%$ and in Group B was $10 \%$, i.e. in Group A, 16 patients and in Group B, 5 patients had vomiting. The incidence of vomiting associated with the use of ketamine is approximately $8 \%$ as studied by Green SM et al in paediatric age group.(27) The higher incidence in our study could be because of maintenance infusion of ketamine in surgeries lasting maximum for thirty five minutes.

In Group B, the incidence of vomiting (10\%) was less compared to Jenstrup $M$ et al study in which the incidence was $20 \%$, this could be because they had used fentanyl infusion throughout the procedure thus increasing the incidence of vomiting.(1) Akbult et al in their study concluded that in upper gastrointestinal endoscopic procedures midazolam-ketamine combination was comfortable as compared to propofol-fentanyl combination but propofolfentanyl combination had fewer side effects.(28)

In both the Groups, recovery of patients was assessed by modified Steward Coma Score, maximum of six. It was seen that points comprising recovery in consciousness level were less in Group A as compared with Group B, than the points comprising the recovery in airway and activity.

In Group A, maximum number of patients i.e. 25 patients had score of six, 15 minutes after stopping ketamine infusion whereas in Group B, 30 patients had score of six, 5 minutes after stopping propofol infusion, similar results were shown by Akbult et al that recovery time was less in propofolfentanyl combination. ${ }^{28)}$

Similar to Irwin MG et al study, it was observed that the patients were calm and quiet at the score of six in Group B.(13) In Group A, 46 patients were fit for discharge within two hours of completion of procedure and out of the 4 patients who were not discharged, 3 patients had severe emergence delirium so they were given sedation by injection diazepam and so could not be sent home. One patient had excessive 
vomiting so was not discharged. In Group B, all patients were fit for discharge except one who had excessive vomiting. At the time of discharge, in both groups, patients were asked about intraoperative awareness. No patient in either group had intraoperative awareness. They were asked whether or not they would be happy to receive the same anaesthetic combinations again. All patients in both the groups were satisfied by the two techniques irrespective of the complications.

\section{CONCLUSION}

Hence, it can be concluded that on comparison of two TIVA techniques, Group B combination is preferred as there are distinct advantages of minimal changes in HR, MAP and the near baseline values are also restored earlier with early recovery, less postoperative complication rate. However, Group B combination possesses the disadvantages of having greater induction time, pain on injection and incidence of intraoperative respiratory depression which is not there in Group A. However, on analysis based on the discharge criterion, it can be concluded that both the techniques are suitable for day care surgery.

\section{REFERENCES}

[1] Jenstrup M, Nielsen J, Fruergard K, et al. Recovery characteristics: comparative study between fentanyl and alfentanyl for TIVA. BJA 1990;64:717-22.

[2] Jakobsson J, Oddby E, Rane K. Patient evaluation of four different combinations of intravenous anaesthetics for short outpatient procedures. Anaesthesis 1993;48(11):1005-07.

[3] Reichl Dl, Silvay G. Ketamine: an update of the first five years of clinical experience. Can J Anaesthesia 1989;36(2):186-97.

[4] White PF. Pharmacological interactions of midazolam and ketamine in surgical patients Clinical Pharmacology and Therapeutics 1982;31:280-1.

[5] Cartwright PD, Pingel SM. Midazolam and diazepam in ketamine anaesthesia. Anaesthesia 1984;39(5):43942.

[6] Toft P, Romer U. Comparison of midazolam and diazepam to supplement total intravenous anesthesia with ketamine for endoscopy. Can J Anaesthesia 1987;34(5):466-9.

[7] Crawford ME, Carl P, Andersen RS, et al. Comparison between midazolam and thiopentone-based balanced anaesthesia for day-case surgery. Br J Anaesthesia 1984;56(2):165-9.

[8] Idvall J, Ahlgren I, Aronsen KR, et al. Ketamine infusions: pharmacokinetics and clinical effects. $\mathrm{Br} \mathrm{J}$ Anaesthesia 1979;51(12):1167-73.

[9] Restall J, Tully AM, Ward PJ, et al. Total intravenous anaesthesia for military surgery. A technique using ketamine, midazolam and vecuronium. Anaesthesia 1988;43(1):46-9.

[10] Bell J, Sartain J, Wilkinson GA, et al. Comparison of propofol and fentanyl anesthesia in coronary artery versus valve surgery. Anaesthesia 1995;50(7):644-8.
[11] Doxon J, Roberts FL, Tackley RM, et al. Study of possible interaction between fentanyl and propofol using a computer-controlled infusion of propofol. $\mathrm{Br} \mathrm{J}$ Anaesthesia 1990;64(2):142-7.

[12] Peacock JE, Luntley JB, O'Connor B, et al. Remifentanil in combination with propofol for spontaneous ventilation anaesthesia. $\mathrm{Br} \mathrm{J}$ Anaesthesia 1998;80(4):509-11.

[13] Irwin MG, Thompson N, Kenny GN. Patientmaintained propofol sedation. Assessment of a targetcontrolled infusion system. Anaesthesia 1997;52(6):525-30.

[14] Michaloliakou C, Chung F, Sharma S. Preoperative multimodal analgesia facilitates recovery after ambulatory laparoscopic cholecystectomy. Anesth Analg 1996;82(1):44-51.

[15] Langrehr D, Agoston S, Endmann W, et al. Pharmacodynamics and reversal of benzodiazepine ketamine, ataranalgesia. South African Medical Journal 1981;59(12):425-8.

[16] White PF. Comparative evaluation of intravenous agents for rapid sequence induction - thiopental, ketamine and midazolam. Anaesthesiology 1982;57(4):279-84.

[17] Klement W, Arndt JO. Pain on injection of propofol: effects of concentration and diluent. $\mathrm{Br} J$ Anaesth 1991;67(3):281-4.

[18] Rolly G, Versichelen L, Huyghe L, et al. Effect of speed of injection on induction of anaesthesia using propofol. Br J Anaesthesia 1985;57(8):743-6.

[19] Chudnofsky CR, Weber JE, Stayonaff PJ, et al. A combination of midazolam and ketamine for procedural sedation and analgesia in adult emergency department patients. Acad Emerg Med 2000;7(3):22835.

[20] White PF, Way WL, Trevor AJ. Ketamine its pharmacology and therapeutic uses. Anaesthesiology 1982;56(2):119-36.

[21] Hernández C, Parramon F, García-Velasco P, et al. Comparative study of 3 techniques for total intravenous anesthesia: midazolam-ketamine, propofol-ketamine and propofol-fentanyl. Revista Española de Anestesiología y Reanimación 1999;46(4):154-8.

[22] Krithika V, Amudharani R, Anandan H. Comparison of ketamine and propofol in combination with fentanyl and midazolam in total intravenous anaesthesia for minor gynecological procedures. International Journal of Scientific Study 2017;5(2):178-80.

[23] Vermeyen KM, De Hert SG, Erpels FA, et al. Myocardial metabolism during anaesthesia with propofol: low dose fentanyl for coronary bypass surgery. $\mathrm{Br} \mathrm{J}$ Anaesthesia 1991;66:504-8.

[24] Gill SS, Wright EM, Reilly CS. Pharmacokinetic interaction of propofol and fentanyl: single bolus injection study. Br J Anaesthesia 1990;65(6):760-5.

[25] Sanderson JH, Blades JF. Multicentre study of propofol in day care surgery. Anaesthesia 1988; (Suppl 43): 70-3. 
[26] Taylor MB, Grounds RM, Dulrooney PD, et al. Ventilatory effects of propofol during induction of anaesthesia: comparison with thiopentone. Anaesthesia 1986;41(8):816-20.

[27] Green SM, Johnson NE. Socioeconomic fact book of surgery. Ambulatory surgery. Chicago: American College of Surgeons 1986:104-5.
[28] Akbulut UE, Saylan S, Sengu B, et al. A comparison of sedation with midazolam-ketamine versus propofolfentanyl during endoscopy in children: a randomized trial. European Journal of Gastroenterology \& Hepatology 2017;29(1):112-8. 